\title{
Towards Prevention of Spinal Cord Injury: The Role of a National Register
}

\author{
E. C. Wigglesworth, DAppSc, DipEd \\ Executive Director, The Menzies Foundation, 210 Clarendon Street, East Mel- \\ bourne, 3002, Australia.
}

\begin{abstract}
Summary
The Menzies Foundation in Australia recently sponsored two technical meetings designed to reduce the incidence of spinal cord injury in the Australia-New Zealand area. From these meetings came unanimous support for the creation of a national Register to develop data and programmes for the prevention of spinal cord injury. The Foundation has since provided further funds for a Planning Committee to bring the Register into being. These developments are described.
\end{abstract}

Key words: Spinal cord injury; Prevention; Australia; Statistical Register.

The Menzies Foundation is a non-political organisation that seeks to commemorate the name of Sir Robert Menzies, who was Prime Minister of Australia from 1939-1941 and again from 1949-1966. The Foundation was formed in 1979 with a medical and scientific emphasis and an objective to promote, through research and innovation, the health and fitness of the Australian community. Its emphasis is firmly in the area of prevention, rather than management, of disease and it operates through a network of State/Territory Committees whose chairmen collectively constitute its National Board. It prefers to work as a catalyst in those areas of health where other organisations are, for various reasons, unable to contribute.

In 1986, a suggestion from the Foundation's Western Australian Committee was endorsed by the Foundation's National Board. It was decided that a small group of technical experts should meet in Perth in November 1987 to develop a technical report similar in style, length and presentation to the customary WHO Reports.

\section{The preliminary task}

The immediate task was to produce a brief but definitive scientific report which would provide a statistical analysis of the incidence and cost of spinal cord injury in Australia, and would also serve as a basis for a later submission (prob- 
ably to Government) in order to achieve the ultimate aim of a reduction in the incidence of spinal cord injury.

\section{The first meeting}

To meet its objective, the Foundation sought support from both technical experts and government authorities. The meeting in Perth was attended by many directors of spinal cord injury units in Australia, by senior officers of the Federal Department of Community Services and Health, by leading academics working in the field and by two distinguished overseas visitors.

Some were asked to act as joint authors of particular chapters: others as chairmen and discussion leaders. Draft papers were circulated to the respective chairmen and discussion leaders, commented on and revised. The revised drafts were then circulated in mid-September, thus allowing almost 2 months for preconference study.

The format of the meeting was designed to permit maximum discussion. Each technical session was of 3 hours duration. The authors were given 20-25 minutes to summarise their findings: the nominated discussion leader commented on the paper which was then open for general discussion during the remaining 2 hours. In practice, the discussions were both lively and constructive and varied from wide ranging comments to minor editorial detail.

The process of extended peer review led to many changes, some major. These were then incorporated into the publication draft of the relevant chapter. The revisions were carried out on the spot by the Foundation Secretariat, thus permitting publication of the final Report within 1 month of the meeting.

As the revisions continued, it became abundantly clear that there was total agreement amongst this group of specialists on three matters:

1. The need for a national Registry of spinal cord injury.

2. The need for a further meeting of appropriate experts to develop the statistical and other details.

3. The need for spinal cord injury to be recognised as a defined area of national importance (thus giving a separate identity for research support).

\section{The first recommendations}

These recommendations were taken to the National Board of the Foundation, which has a medical orientation. It appreciated that any comprehensive programme for the control of a public health problem requires, as a basic strategy, a study of the distribution of its frequency and a search for its determinants. It also agreed that this fundamental strategy depends for its success on the availability of comprehensive and compatible data.

After an extensive discussion, the Board wholeheartedly agreed that a national Registry of spinal cord injury should be established in Australia. The purpose of the Registry would be to identify areas where preventive measures might be successful and also to monitor the effects of such measures.

In addition, the very establishment of such a Registry would stimulate research into new preventive programmes. These might include projects in the fields of sociology, biomechanics, epidemiology, and law as well as medicine. 


\section{Implementation}

Following the meeting, a deputation including Sir George Bedbrook and led by Sir William Refshauge (the Editor-in-Chief of the Technical Report) called on the Minister for Community Services and Health, the Honourable Dr Neal Blewett. The Minister agreed that the cost of spinal cord injury was high in both human, social and financial terms. He also accepted that the actual numbers were relatively small so that if the data were to be adequate for statistical treatment, there should be a comprehensive compatible data set for the whole of Australia. He then made a spontaneous offer of assistance towards the development of a second Technical Meeting 'Towards a Registry for the Prevention of Spinal Cord Injuries'.

\section{The second meeting}

The second technical meeting, under the auspices of the Menzies Foundation with some financial support from the Commonwealth Department of Community Services and Health was held in Perth in May 1988. In similar fashion to the first meeting, it was attended by Directors from the specialised Spinal Injuries Units in each State, by senior officers of Commonwealth and State Governments, and by leading Australian and overseas academics in the field.

The format of the meeting also followed the earlier model: pre-circulated papers; short presentations; lengthy peer review, and swift publication.

\section{The second recommendations}

After extensive discussion of the pre-circulated papers and on the evidence presented to it, the meeting expressed deep concern at the present high incidence of spinal cord injury in Australia; identified a special place for Australia and New Zealand in reducing the high incidence nationally and internationally; and welcomed the priority accorded to injury prevention in the recent 'Health for All' report (Leeder, 1988).

It affirmed that the first requirement was the establishment of a Spinal Cord Injury Register and a Registry. It unanimously recommended that the Register should provide comprehensive information for programmes of work to reduce the incidence of spinal cord injury, and that a Spinal Cord Injury Registry should be established to compile and maintain this Register, and to carry out prevention-related tasks.

It also asked the Menzies Foundation to establish a Planning Committee to bring the Registry into being.

\section{The planning committee}

Once again, these recommendations were taken to the Foundation Board where they were heartily endorsed. The Board established a Planning Committee, under the Chairmanship of Sir William Refshauge and voted further funds for Committee use to bring the Registry into being.

The Committee is currently preparing a submission on the location, funding, 
structure, and staffing of the proposed Register together with a plan for its staged development. In addition, the Chairman and Secretary are planning to visit every capital city to ascertain the interest of the Ministers for Health and the stance of the Department of Healths in all States and Territories. Those individual responses will then be incorporated into the final submission.

Finally, in order to enhance the quality of the data set, the Committee is planning to recommend that spinal cord injury be declared a notifiable disease in Australia.

\section{Conclusion}

Australia has six specialised spinal cord injury units. It therefore has the potential for producing a comprehensive set of statistical information on the causes and circumstances of those events that result in spinal cord injury. In the past it was not possible to capitalise on this potential advantage since each Unit was responsible to its State authority, and there was insufficient liaison between the States.

With this new mix of enthusiastic medical directors, senior academics and government officials (from both Federal and State spheres), welded into a cohesive and influential unit and with an alliance with an impartial but concerned organisation, it now seems likely that Australia will soon have a National Register for the Prevention of Spinal Cord Injury.

\section{References}

LEEDER SR, (Chairman) 1988 Health for All Australians. Report to the Australian Health Ministers Advisory Council. Department of Community Services and Health, Canberra. ReFshaUge WJ, (ed) 1987 Towards prevention of spinal cord injury. Menzies Foundation, Melbourne.

REFSHAUGE WJ, (ed) 1988 Towards a registry for the prevention of spinal cord injury. Menzies Foundation, Melbourne.

\section{Appendix}

\section{The Planning Committee}

The Chairman of the Planning Committee is Sir William Refshauge, a previous Director-General of the Federal Department of Health, who was nominated by the Menzies Foundation Board to be Chairman for both the Perth meetings and to be Editor-in-Chief for both Technical Reports. The other members are Sir George Bedbrook (Emeritus Orthopaedic and Spinal Consultant, Royal Perth Rehabilitation Hospital and previously President of the International Medical Society of Paraplegia), Professor R. S. B. Gye (Dean, Faculty of Medicine, University of Sydney and Chairman of the Foundation's Medical and Scientific Advisory Committee), and Dr L. R. Smith (Director of the Australian Institute of Health). It is serviced by Dr E. C. Wigglesworth (Executive Director of the Menzies Foundation) as its Secretary. 